\title{
CONTENTS OF VOLUME 4
}

\section{NUMBER 1}

1 Reactor Characteristics Related to Moderate or Intense Low-Oxygen Dilution for Clean/Cleaning Combustion Plants

M. De Joannon, G. Langella, F. Beretta, A. Cavaliere, and C. Noviello

21 Mitigation of $\mathrm{CO}_{2}$ Emissions Using Low and Near Zero $\mathrm{CO}_{2}$ Emission Power Plants

P. Mathieu

$37 \mathrm{~N}_{2} \mathrm{O}$ Reduction in a Bubbling Fluidized Bed Reactor by Injection of Hydrocarbon Fuels

Hao Liu and Bernard M. Gibbs

53 Simulation of the FGD in-Duct Injection Process at Low

Temperatures with Competitive Reactions

J. A. Marques, J. L. Herrera, A. Garea, and A. Irabien

\section{NUMBER 2}

71 The Devolatilization Step during the Fluidized Bed Conversion of a Biomass

M. L. Mastellone, F. Perugini, M. Ponte and U. Arena

87 Efficiency Analysis of a Boiler for Suspension Burning of Sugar Cane Bagasse

A. L. Brito, P. Beaton, J. Ballester, and C. Dopazo

97 Environmentally Friendly Bus Technologies

B. Eberwein

115 Mechanisms of Fire Suppression by Halons and Halon

Replacements: a Review

G. M. Faeth, C. H. Kim and O. C. Kwon 


\section{NUMBER 3}

187 Public Transport and $\mathrm{CO}_{2}$ Emission: a Comparative Assessment between Conventional and Innovative Vehicles

A. Genovese and R. Ragona

203 Power Generation for a Cleaner Environment - a Perspective G. J. Kelsall and C. D. Soothill

223 Source PM2.5 Characterization - Initial Results and Some Important Parameters in Fine Particulate Measurement from Oil and Coal Combustion

S. Win Lee and B. Kan

$239 \mathrm{NO}_{\mathbf{x}}$ Formation in Grate Combustion of Wood

$J$. J. Saastamoinen and R. Taipale

269 Air Quality Index and Its Interpretation for the City of Delhi M. Sharma, R. Pandey, M. Maheshwari, B. Sengupta,

B. P. Shukla and A. Mishra

\section{NUMBER 4}

285 Effects of Jet Dilution and Co-Flow on Sooting and Emission Characteristics of Hydrocarbon Fuels

S. F. Goh, S. Kusadome, and S. R. Gollahalli

$303 \mathrm{NO}_{x}$ Formations in Diluted $\mathrm{CH}_{4} / \mathrm{H}_{2}$ Counterflow Diffusion Flames G. J. Rørtveit, J. E. Hustad, and F. A. Williams

315 Batch Operated Gasification and Oxidation Process for the Recovery of Precious Metals

R. Berger, G. Baumbach, U. Demant, and H. Knosp

335 Reactedness-Mixture Fraction Presumed PDF Computations of Local Extinction Effects in Piloted Jet Flames of Methanol Fuel Blends

P. Koutmos and P. Marazioti

357 Author Index

358 Table of Contents 